\title{
Pancreatic intraductal papillary mucinous neoplasm with concomitant heterotopic pancreatic cystic neoplasia of the stomach: a case report and review of the literature
}

\author{
Dimitrios Tsapralis ${ }^{1,3}$, Alexandros Charalabopoulos ${ }^{1,3}$, Eva Karamitopoulou ${ }^{2,3}$, Dimitrios Schizas ${ }^{1,3}$, \\ Konstantinos Charalabopoulos ${ }^{2,3^{*}}$, Theodoros Liakakos ${ }^{1,3}$, Anastasios Macheras ${ }^{1,3}$
}

\begin{abstract}
A 60-year-old Caucasian male underwent a total pancreatectomy for a mixed type pancreatic intraductal papillary mucinous neoplasm (IPMN) arising in the main and secondary pancreatic ducts. During surgery, a subserosal polypoid mass was noted at the greater curvature of the gastric antrum and was enucleated. This mass was proven to be heterotopic pancreatic tissue with cystic neoplasia of the IPMN histologic subtype. Through an extensive search of the literature, we found that this is the first case ever reported with simultaneous existence of IPMN changes, in the main and secondary ducts of the orthotopic pancreas and in the heterotopic pancreatic tissue of the gastric wall.
\end{abstract}

\section{Introduction}

Recent literature suggests either an increasing incidence of cystic neoplasms of the pancreas, or improved detection and recognition of these lesions. Historically, autopsy studies have revealed a significant prevalence of cystic lesions of the pancreas. Kimura et al [1] found cystic lesions in $24 \%$ of 300 consecutive autopsy specimens among an elderly Japanese population. The most significant recent change in the diagnosis and treatment of pancreatic cystic neoplasms is the recognition of intraductal papillary mucinous neoplasm (IPMN) as a distinct pathologic entity [2-6]. First reported in the literature by Ohashi et al [7], it was classified as a distinct entity from other mucin-producing cystic neoplasms of the pancreas by the World Health Organization (WHO) in 1996 [8]. Characteristic features of IPMN according to WHO include a tall, columnar epithelium with marked mucin production, and cystic transformation of either the main pancreatic duct or one of its side branches $[8,9]$.

Despite the fact that IPMNs have become the second most common cause of pancreatic resections at many

\footnotetext{
* Correspondence: kcharala@cc.uoi.gr

${ }^{2}$ Department of Pathology, Athens University Medical School, Attikon University Hospital, Athens, Greece
}

large centers [10], the incidence of this pathologic entity in heterotopic pancreatic tissue is extremely rare. It is not unusual to find pancreatic tissue in the stomach, duodenum, ileum, Meckel's diverticulum or at the umbilicus. Feldman and Weinberg [11] found duodenal pancreatic tissue in $13,7 \%$ of 410 necropsy specimens. Pearson [12] estimated that heterotopic pancreatic tissue could be found in as many as $2 \%$ of autopsies if it were sought carefully. In spite of the relatively common presence of heterotopic pancreas, mainly as a silent gastrointestinal malformation, a systematic review of the literature has revealed only one reported case of papillary mucinous neoplasm in gastric polypoid tumor containing heterotopic pancreatic tissue [13].

Herein, we report a case of pancreatic IPMN from the main and secondary pancreatic ducts with simultaneous existence of a gastric polypoid tumor containing heterotopic pancreatic tissue with cystic neoplasia of the same histologic subtype.

\section{Case report}

A 60-year-old man visited his physician because of a skin discoloration suggestive of jaundice, dark urine and pale stools. The patient also reported vague epigastric 
pain, with onset about 6 months prior to the onset of icterus. He denied any fever or weight loss. His medical history also included hypertension, diabetes mellitus and tuberculosis. A complete blood cell count was taken, which revealed no abnormality, while the blood chemistry profile demonstrated direct hyperbilirubinemia (total bilirubin, TBIL:20 mg/dl, direct bilirubin, DBIL:16 mg/ dl) and a remarkable elevation of the alkaline phosphatase (ALP) and gamma-glutamyl transpeptidase (GGT) (the levels of aspartate transaminase (AST) and alanine transaminase (ALT) were only mildly elevated). The patient was subjected to ultrasound examination of his abdomen which disclosed a cystic mass in the head of the pancreas and a dilatation of the common bile duct $(1.7 \mathrm{~cm})$ and intrahepatic bile ducts.

The patient was further evaluated with T1-weighed and T2-weighed gadolinium ((Gd)-DTPA)-enhanced MRI images and MRCP, which revealed a cystic lesion in the pancreatic head with maximum transverse diameter of 5 $\mathrm{cm}$. The pancreatic cyst was in communication with a clearly dilated main pancreatic duct. In parallel with the dilatation of the main pancreatic duct along its entire course, a significant dilatation of secondary ducts (sidebranches) was also documented (Figure 1). The imaging findings were compatible with the diagnosis of a diffusely distributed intraductal papillary mucinous neoplasm (IPMN) of the mixed-type variety. Moreover, the ultrasonographic finding of the dilated intra- and extra-hepatic biliary tree was confirmed, with maximum diameter of the common bile duct at about 1,7 cm. Due to the level of icterus and the coexisting dilation of the common bile duct (CBD), the patient was subsequently subjected to ERCP with simultaneous insertion of a plastic stent into the CBD. During the upper gastrointestinal endoscopy, only a mild esophagitis of the lower third of the esophagus

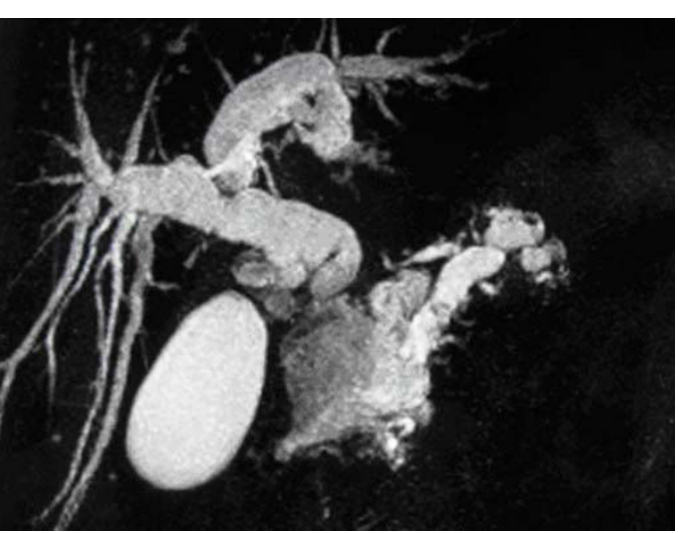

Figure 1 MRCP showing pancreatic cyst in the head of the organ with dilation of the main and branch pancreatic ducts as well as of the extra- intra hepatic biliary tree. was diagnosed, with no indication of a gastric wall abnormality reported.

After the aforementioned complete work-up of the patient, he was referred to our Surgical Department for surgical treatment. Because of the diffuse distribution of the cystic neoplasm, a total pancreatectomy, splenectomy and limited partial gastrectomy was performed. Incidentally a subserosal polypoid tumor was found at the greater curvature of the gastric antrum. Local excision of the gastric tumor was performed and it was also sent for histologic examination. On the $6^{\text {th }}$ postoperative day, the patient presented a biliary leak which was managed conservatively. He was discharged on the $40^{\text {th }}$ day, and 1 year after the operation has been disease and symptom free.

Histologic examination of the orthotopic pancreas revealed a non-invasive intraductal papillary mucinous neoplasm involving the main pancreatic duct, with prominent intraductal papillary projections (Figure 2a). The papillae were well-developed with a fibrovascular core. The neoplastic epithelial cells showed intestinal differentiation. The neoplasm exhibited significant architectural and nuclear atypia. There was budding off of clusters of neoplastic cells into the lumen, as well as, significant nuclear pleomorphism with loss of polarity and prominent nucleoli (IPMN with high grade dysplasia; figure $2 \mathrm{~b}$ ).

Additionally, a $2.5 \times 2.2 \times 0.9 \mathrm{~cm}$ measuring tissue specimen from the gastric wall was received. Macroscopic evaluation revealed a $1.5 \mathrm{~cm}$ white nodule with cystic spaces. Histological examination demonstrated heterotopic pancreatic tissue consisting of well-formed lobules of pancreatic acini and cystically dilated ducts containing intraluminal papillae (Figure $3 \mathrm{a}, \mathrm{b}$ ). The papillary structures were lined by mucinous epithelium with focal intestinal metaplasia and mild to moderate nuclear atypia (Figure 3b, c).

\section{Discussion}

IPMNs account for 7-35\% of all the cystic neoplasms of the pancreas in published surgical series $[14,15]$. In contrast to patients with serous cystic neoplasms (SCN) or mucinous cystic neoplasms (MCN), patients with IPMN tend to be older, with a mean age at presentation of approximately 65 years. In the differential diagnosis of IPMN MCN and pancreatic intraepithelial neoplasia (PanIN) must be included [16,17]. MCNs usually can be distinguished by the lack of pancreatic ductal structures and their characteristic ovarian-like stroma. Distinction of IPMNs from PanINs may be more difficult and has been the subject of an international consensus conference in August 2003 [17]. While IPMNs are of macroscopically visible size, PanINs are microscopic findings involving ducts less than $5 \mathrm{~mm}$ [17]. Moreover, IPMNs often express the mucin MUC-2, while PanINs usually express MUC-1. 

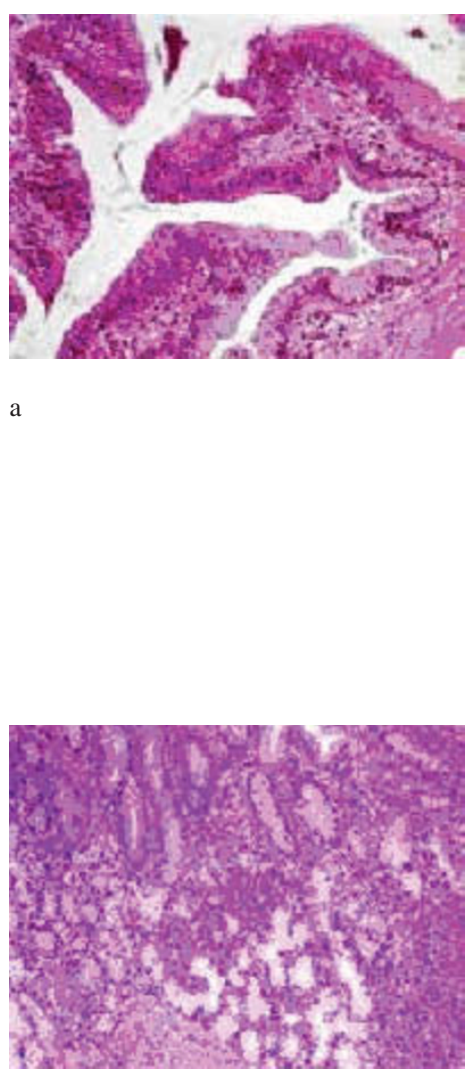

Figure 2 IPMN in orthotopic pancreas. a. Well-developed papillary projections within the duct. There is architectural and nuclear atypia. $(H+E \times 200)$, b. Budding off of clusters of neoplastic cells into the lumen $(H+E \times 400)$.

Heterotopic pancreas, on the other hand, is defined as pancreatic tissue that lacks direct or vascular connection to normal pancreas [18]. In autopsy series, the prevalence of this congenital condition ranges from $0,55 \%$ to $13,7 \%$ [19]. Clinically, pancreatic heterotopia is observed in one out of 500 upper abdominal operations [20]. Pearson et al [12] reviewed 589 cases of heterotopic pancreas, and reported the frequencies of this disorder as follows: $30 \%$ in the duodenum, $25 \%$ in the stomach, $15 \%$ in the jejunum, $3 \%$ in the ileum and 6\% in Meckel's diverticulum. Particularly in the stomach, heterotopic pancreatic tissue predominantly develops in males between 30 and 50 years of age. The majority of cases identified in the stomach are submucosal tumors, located in the antrum [21].

The presence of heterotopic pancreas is usually asymptomatic, but it is capable of producing symptoms, depending on its location and size [22]. Several cases have been reported in the literature presenting as gastric outlet obstruction, small bowel obstruction, upper gastrointestinal bleeding or obstructive jaundice [23-26].

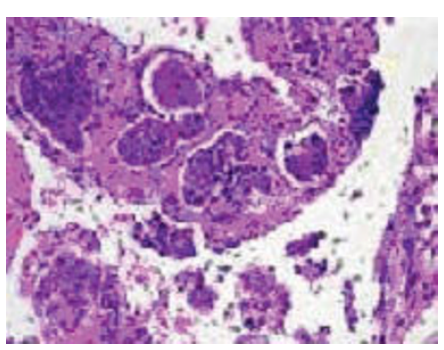

a

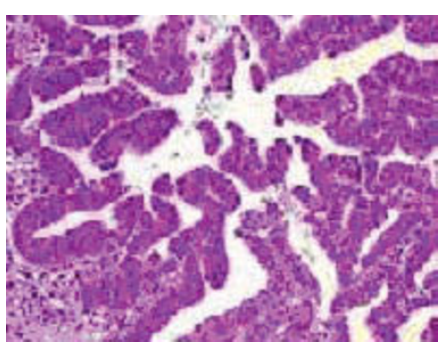

b

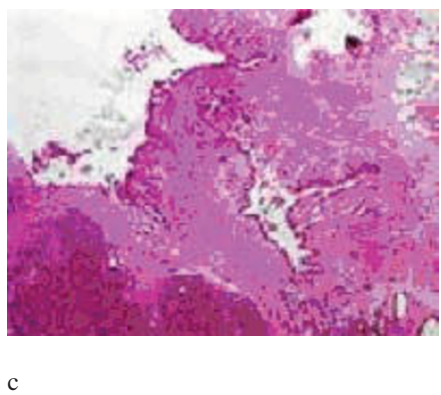

Figure 3 a. Ectopic pancreatic tissue within the gastric wall $(\mathbf{H}$ $+\mathrm{E} \times 100)$, b. and $\mathrm{c}$. Cystically dilated ducts containing intraluminal papillae. The papillary structures are lined by mucinous epithelium with nuclear atypia, consistent with IPMN $(\mathrm{H}+\mathrm{E} \times 400)$.

Adenocarcinoma, islet cell tumors and cystic tumors have also been reported in heterotopic pancreas [19,27-29].

In the literature, there are few reported cases of malignant change of ectopic gastric pancreas [30,31]. The majority of these cases represent adenocarcinoma, while papillary mucinous neoplasia, of whatever histologic subtype, has been reported in only one case so far [13]. The present case is the first reported with the unique characteristic of simultaneous existence of IPMN (of the mixed pancreatic duct type) and IPMN or PanIN of the heterotopic gastric pancreatic tissue. Our case satisfies the minimal diagnostic criteria for tumors that arise in heterotopic pancreatic tissue initially proposed by Guillou and colleagues [29] which state that: i. the tumor must be found within or 
close to the ectopic pancreas, ii. direct transition between pancreatic structures and carcinoma must be observed (ie duct cell dysplasia or carcinoma in situ), iii. the nonneoplastic pancreas must comprise at least fully developed acini and ductal structures, and iv. direct extension or metastasis from an other site must be excluded.

The differential diagnosis in this case (as regards the ectopic gastric pancreatic tissue) includes low-grade intraepithelial neoplasia and small IPMN. As previously emphasized such distinction is impossible at times and currently is based on size and macroscopic appearance [32]. Since the lesion described was noted on gross inspection of the surgical specimen, we believe that the designation of intraductal papillary mucinous neoplasm would be more appropriate. Moreover, the papillary excrescences are larger than those typically seen in PanIN.

The preoperative diagnosis of heterotopic pancreas is challenging despite the advances in imaging technology. Heterotopic pancreas usually presents in upper gastrointestinal series as a well-delineated submucosal filling defect with a central indentation [20,33,34]. Endoscopically, the lesion is seen as a submucosal tumor with a central umbilication. The CT imaging of an ectopic pancreas enhances brightly as an orthotopic pancreas [29,35].

Given its clinically insidious course, heterotopic pancreas is usually an incidental finding, either intraoperativelly, or during radiographic or endoscopic examination of the upper gut. When found at the time of laparotomy (as in our case), local excision, with or without frozen section, rather than radical resection is the preferred way of treatment $[25,33,36]$. Potentially, however, the documentation of underlying malignancy based on the implemented frozen section analysis, sets the dilemma of performing a more radical surgical treatment in order to prevent re-operation or diagnostic difficulties.

\section{Consent}

Written informed consent was obtained from the patient for publication of this case report and accompanying images. A copy of the written consent is available for review by the Editor-in-Chief of this journal.

\footnotetext{
Author details

${ }^{1}$ Third Department of Surgery, Athens University Medical School, Attikon University Hospital, Athens, Greece. ${ }^{2}$ Department of Pathology, Athens University Medical School, Attikon University Hospital, Athens, Greece. ${ }^{3}$ Department of Physiology, Clinical Unit, Ioannina University Medical School, loannina, Greece.
}

\section{Authors' contributions}

The patient was examined and operated by DT, AC, DS, TL and AM. The same authors are responsible for the post-operative care and follow up. EK performed the histopathological examination. KC was responsible for the main conception, the design and the literature review. This manuscript was drafted by DT, AC and DS, who also collected all relevant patient data, and were supervised by $T L$ and AM. EK provided the microscopic figures and the relevant text. All authors contributed to its critical review and all approved the final draft.

\section{Competing interests}

The authors declare that they have no competing interests.

Received: 25 September 2009

Accepted: 14 January 2010 Published: 14 January 2010

References

1. Kimura W, Nagai $H$, Kuroda A, Muto $T$, Esaki $Y$ : Analysis of small cystic lesions of the pancreas. Int J Pancreatol 1995, 18:197-206.

2. Chari ST, Yadav D, Smyrk TC, DiMagno EP, Miller LJ, Raimondo M, Clain JE, Norton IA, Pearson RK, Petersen BT, Wiersema MJ, Farnell MB, Sarr MG: Study of recurrence after surgical resection of intraductal mucinous neoplasms of the pancreas. Gastroenterology 2002, 123:1500-1507.

3. Furukawa T, Klöppel G, Volkan Adsay N, Albores-Saavedra J, Fukushima N, Horii A, Hruban RH, Kato Y, Klimstra DS, Longnecker DS, Lüttges J, Offerhaus GJ, Shimizu M, Sunamura M, Suriawinata A, Takaori K, Yonezawa S: Classification of types of intraductal papillary-mucinous neoplasm of the pancreas: a consensus study. Virchows Arch 2005, 447:794-799.

4. Fernadez-del Castillo C: Surgical treatment of intraductal papillary mucinous neoplasms of the pancreas: the conservative approach. J Gastroint Surg 2002, 6:660-661.

5. Terris B, Ponsot P, Paye F, Hammel P, Sauvanet A, Molas G, Bernades P, Belghiti J, Ruszniewski $P$, Fléjou JF: Intraductal papillary mucinous tumors of the pancreas confined to secondary ducts show less aggressive pathologic features as compared with those involving the main pancreatic duct. Am J Surg Pathol 2000, 24:1372-1377.

6. Kobari M, Egawa S, Shibuya K, Shimamura H, Sunamura M, Takeda K, Matsuno S, Furukawa T: Intraductal papillary mucinous tumors of the pancreas comprise 2 clinical subtypes: differences in clinical characteristics and surgical management. Arch Surg 1999, 134:1131-1136.

7. Ohashi K, Murakimi Y, Maruyama M, Takekoshi T, Ohta H, Ohashi I: Four cases of mucous secreting pancreatic cancer. Prog Dig Endosc 1982 20:348-351.

8. Kloppel G: Histological typing of tumors of the exocrine pancreas. World Health Organization International Classification of Tumors Berlin: Springer 1996, 11-20.

9. Sohn TA, Yeo CJ, Cameron UL, Hruban RH, Fukushima N, Campbell KA: Intraductal papillary mucinous neoplasms of the pancreas: An updated experience. Annals of Surgery 2004, 239:788-797.

10. Sarr MG, Murr M, Smyrk TC, Yeo CY, Fernandez del Castillo C, Hawes RH: Primary cystic neoplasms of the pancreas. Neoplastic disorders of emerging importance-current state of the art and unanswered questions. J Gastroint Surg 2003, 7:417-428.

11. Feldman $M$, Weinberg $T$ : Aberrant pancreas; cause of duodenal syndrome. JAMA 1952, 148:893.

12. Pearson S: Aberrant pancreas. Review of the literature and report of 3 cases, one of which produced common and pancreatic duct obstruction. Arch Surg 1951, 63:168-172.

13. Phillips J, Katz A, Zopolsky P: Intraductal papillary mucinous neoplasm in an ectopic pancreas located in the gastric wall. Gastroint Endosc 2006, 5:64-69.

14. Spinelli KS, Fromwiller TE, Daniel RA, Kiely JM, Nakeeb A, Komorowski RA: Cystic pancreatic neoplasms: observe or operate. Ann Surg 2004, 239:651-657.

15. Allen PJ, Jaques DP, D'Angelica M, Bowne WB, Konlon KC, Brennan MF: Cystic lesions of the pancreas: selection criteria for operative and nonoperative management in 209 patients. J Gastroint Surg 2003, 7:970-977

16. Adsay NV: Intraductal papillary mucinous neoplasms of the pancreas: pathology and molecular genetics. J Gastroint Surg 2002, 6:656-659.

17. Hruban RH, Takaori K, Klimstra DS, Adsay NV, Albores-Saavedra J, Biankin AV, Biankin SA, Compton C, Fukushima N, Furukawa T, Goggins M, Kato Y, Klöppel G, Longnecker DS, Lüttges J, Maitra A, Offerhaus GJ, Shimizu M, Yonezawa S: An illustrated consensus on the classification of pancreatic intraepithelial neoplasia and intraductal papillary mucinous neoplasms. Am J Surg Pathol 2004, 2:977-987. 
18. Chou SJ, Yu Wei C, Hsiang Chun J, Victor C, Tsu Hing C: Ectopic pancreas in the ampulla of Vater with obstructive jaundice. Digest Surg 2006, 23:262-264.

19. Biswas A, Husain E, Feakins R, Abraham AT: Heterotopic pancreas mimicking cholangiocarcinoma. JOP 2007, 8:28-34.

20. Barbosa JC, Dockerty M, Waugh JM: Pancreatic heterotopia. Review of the literature and report of 41 authenticated cases of which 25 were clinically significant. Surg Gynec Obst 1946, 82:527-542.

21. Burke GW, Birde SC, Barron AM, Dracht PL, Umlas J: Heterotopic pancreas: Gastric outlet obstruction secondary to pancreatitis and pancreatic pseudocyst. Am J Gastroent 1989, 84:52-55.

22. Armstrong $C P$, King PM, Dixon JM, Macleod IB: The clinical significance of heterotopic pancreas in the gastrointestinal tract. Br J Surg 1981, 68:384-387.

23. Maisonnette F, Abita T, Lachachi F: Aberrant pancreas: report of five cases. Ann Chir 2004, 129:241-243.

24. Eisenberger CF, Kropp A, Langwieler TE, Grocht A, Izbicki JR, Knoetel WT: Heterotopic pancreatitis: gastric outlet obstruction due to an intramural pseudocyst and hamartoma. J Gastroenterol 2002, 40:259-262.

25. Moen J, Mack E: Small bowel obstruction caused by heterotopic pancreas in an adult. Am Surg 1989, 55:503-504.

26. Chandra N, Campbell S, Gibson M, Reece-Smith H, Mee A: Intussusception caused by a heterotopic pancreas: case report and literature review. JOP 2004, 5:476-479.

27. Hickman DM, Frey CF, Carson JW: Adenocarcinoma arising in gastric heterotopic pancreas. West J Med 1981, 135:57-62.

28. Cates J, Williams T, Suriawinata A: Intraductal papillary mucinous adenoma that arises from pancreatic heterotopia within a Meckel diverticulum. Arch Pathol Lab Med 2005, 3:67-69.

29. Guillou L, Nordback P, Gerber C, Schneider RF: Ductal adenocarcinoma arising in a heterotopic pancreas situated in a hiatal hernia. Arch Pathol Labor Med 1994, 118:567-571.

30. Emerson L, Layfield LJ, Rohr LR, Dayton MY: Adenocarcinoma arising inn association with gastric heterotopic pancreas. A case report and review of the literature. J Surg Oncol 2004, 87:53-57.

31. Matsuki M, Gouda Y, Ando T, Matsutka H, Morita T, Uchida N, Kuriyama S. Adenocarcinoma arising from aberrant pancreas in the stomach. $J$ Gastroenterol 2005, 40:652-656.

32. Takaori K, Kobashi Y, Matsusue S, Matsui K, Yamamoto T: Clinicopathologic features of pancreatic intraepithelial neoplasms and their relationship to intraductal papillary mucinous tumors. J Hepatobiliary Pancreat Surg 2003, 10:125-136.

33. Dolan RV, Re Mine WH, Dockerty MB: The fate of heterotopic pancreatic tissue. A study of 212 patients. Arch Surg 1974, 109:762-765.

34. Park SH, Han JK, Choi Bl, Kim M, Kim Yl, Yeon KM, Han MC: Heterotopic pancreas of the stomach: $\mathrm{CT}$ findings correlated with pathological findings in six patients. Abdom Imaging 2000, 25:119-123.

35. Cho JS, Shin KS, Kwon ST, Kim JW, Song CJ, Noh SM, Kang DY, Kim HY, Kang HK: Heterotopic pancreas in the stomach: CT findings. Radiology 2000, 217:139-144

36. Erkan N, Vardar E, Vardar R: Heterotopic pancreas: report of two cases. JOP 2007, 8:588-891.

doi:10.1186/1746-1596-5-4

Cite this article as: Tsapralis et al:: Pancreatic intraductal papillary mucinous neoplasm with concomitant heterotopic pancreatic cystic neoplasia of the stomach: a case report and review of the literature. Diagnostic Pathology 2010 5:4.

Publish with Bio Med Central and every scientist can read your work free of charge

"BioMed Central will be the most significant development for disseminating the results of biomedical research in our lifetime. "

Sir Paul Nurse, Cancer Research UK

Your research papers will be:

- available free of charge to the entire biomedical community

- peer reviewed and published immediately upon acceptance

- cited in PubMed and archived on PubMed Central

- yours - you keep the copyright 